\title{
Diabetes Concordant Comorbidities and Associated Factors Among Adult Diabetic Out-Patients at Hiwot Fana Specialized University Hospital, Harar, Eastern Ethiopia: a Cross-Sectional Study
}

\author{
Abdisa Ejeta' \\ Tekabe Abdosh' \\ Behailu Hawulte (iD ${ }^{2}$ \\ Adugna Lamessa (D) \\ Meseret Belete Fite ${ }^{3}$ \\ Gelana Fekadu (1D ${ }^{4}$ \\ 'School of Medicine, College of Health \\ and Medical Science, Haramaya \\ University, Harar, Ethiopia; ${ }^{2}$ School of \\ Public Health, College of Health and \\ Medical Science, Haramaya University, \\ Harar, Ethiopia; ${ }^{3}$ Department of Public \\ Health, Institute of Health Science, \\ Wollega University, Nekemte, Ethiopia; \\ ${ }^{4}$ School of Nursing and Midwifery, \\ College of Health and Medical Science, \\ Haramaya University, Harar, Ethiopia
}

Background: Nowadays diabetic comorbidities constitute a major public health problem in Ethiopian context. However, there is a dearth in epidemiology and risk factors of diabetic comorbidity in Ethiopia, particularly in the study setting. Therefore, this study was conducted to determine the prevalence and identify factors associated with concordant diabetic comorbidities among diabetic out-patients at Hiwot Fana Specialized University Hospital (HFSUH), EasternEthiopia.

Methodology: A hospital-based cross-sectional study was conducted by reviewing medical record charts of adult diabetic outpatients. Bivariable and multivariable logistic regression analysis was carried out by using STATA version 16.0. To measure the strength of association an Adjusted Odds Ratio (AOR) with 95\% Confidence Interval (CI) was used. Moreover, variables with p-value $\leq 0.05$ were considered as statistically significant with the outcome variable.

Results: In this study, it is found that the overall prevalence of concordant comorbidity among adult diabetic out-patients was 55.8\% (95\% CI: 50.3-61.3). Moreover, more than two-third of patients, $72.73 \%$ were diagnosed for type two diabetic mellitus (T2DM). Among specified comorbidities about $42.3 \%$ were hypertension, $21.63 \%$ were obesity, and $13 \%$ were multi-morbidity. Age $\geq 55$ years (AOR: $7.52,95 \%$ CI: 1.24, 45.75), T2DM (AOR: $9.01,95 \%$ CI: 1.50, 54.04), 2-5 years duration of treatments (AOR: 0.23, 95 CI: 0.078, 0.691), and poor glycemic control (AOR: 4.4 1, 95\% CI: 2.34, 8.32) were factors significantly associated with concordant diabetic comorbidity.

Conclusion: From the study conducted, the higher prevalence of concordant comorbidity among diabetic patients was investigated. Furthermore, older in age, T2DM, prolonged duration of treatment, and poor glycemic control were factors associated with diabetic comorbidities. Early detection and appropriate treatment of diabetic comorbidities are very important for better patient's quality of life and functionality.

Keywords: diabetes mellitus;, concordant comorbidity, diabetic complications, risk factors, Ethiopia

\section{Introduction}

Diabetes mellitus (DM) is a heterogeneous chronic metabolic disorder, which has common characteristics of persistent hyperglycemia with disturbance of carbohydrate, protein, and fat metabolism occurred due to absolute or relative deficiency of insulin. ${ }^{1}$ This can exist in two forms:Type 1 Diabetes Mellitus (T1DM) and Type 2 Diabetes Mellitus (T2DM). ${ }^{2}$
Correspondence: Gelana Fekadu

School of Nursing and Midwifery, College of Health and Medical Science, Haramaya University, Harar, Ethiopia

Tel +251933316505

Email fekadugelana4@gmail.com 
It is clearly observed that the global burden of diabetes had increased significantly since $1990 .^{3}$ Accordingly, both the trend and magnitude of diabetes-related disease burden varied substantially across the regions and the countries. ${ }^{4}$ For instance, in 2017, the global, prevalence, death, and disability-adjusted life-years (DALYs) associated with diabetes were 476 million, 1.37 million, and 67.9 million, with a projection to 570.9 million, 1.59 million, and 79.3 million in 2025 , respectively. ${ }^{5}$ On the other hand, the prevalence of DM is expected to be 28 million by 2030 with a predominant T2DM in Africa. ${ }^{4}$

In the case of Ethiopia, the International Diabetes Federation (IDF) reported that there were more than 2.6 million diabetic cases by $2017 .{ }^{6}$ However, the systematic review and meta-analysis study results showed $2 \%$ to $6.5 \%$ prevalence of $\mathrm{DM}^{7}$ Moreover, studies showed that diabetes of all types can lead to comorbid complications and increase the risk of premature death. ${ }^{4}$

Diabetes comorbidity is defined as the existence of one or more chronic conditions in diabetic patients which can be classified as concordant and discordant comorbidities. ${ }^{8}$ In this context, concordant comorbidities are two or more diseases that share similar pathophysiological characteristics and are more likely to be the focus of the same disease. However, if the pathophysiological feature is not similar, it is called discordant comorbidity. ${ }^{9}$ Thus, hypertension, obesity, hyperlipidemia, Chronic Vascular Disease (CVD), and Chronic Kidney Disease (CKD) are commonly reported comorbidities among diabetic patients. $^{10-14}$

Furthermore, the studies identified that most adults with diabetes have at least one comorbidity and as many as $40 \%$ of them have at least three comorbidities. ${ }^{15}$ According to the study conducted among more than 1.3 million participants, more than $97.5 \%$ of patients had at least one comorbid condition. But, in addition to DM, $88.5 \%$ of them had at least in two comorbid condition. ${ }^{16}$ This situation is highly increasing in sub-Saharan Africa with a range from $6 \%$ to $64 \% .^{17}$

However, there are multiple factors which are associated to the diabetic comorbidities. For instance, urban residence, higher economic status, ${ }^{18}$ diabetes duration, hyperglycemia, age, ${ }^{19}$ waist circumference, ${ }^{11}$ and family history of diabetes are the key examples. ${ }^{20}$

Studies evidenced that diabetic comorbidities increase in the demand for health care, cost of the hospitalizations, and the frequency of medical follow up. ${ }^{4,10,21}$ Therefore, having a better understanding of common diabetic comorbidities and associated factors can enhance the comprehensive management of diabetic patients and the selection of treatment types. ${ }^{22}$ These also enable us topredict the future health care burdens of patients with DM.

In relation to this, the integrated diabetes care guidelines should give more emphasis for both early identification and management of comorbidities. ${ }^{23}$ Thus, timely identification and treatment of comorbidities has been shown to prevent the development and progression of diabetic complications to increase the patient's life expectancy and quality of life too. ${ }^{6}$

However, there is no study in Ethiopia, particularly in eastern part of the country, to clearly indicate the magnitude of concordant comorbidities and risk factors. Therefore, this study was conducted to determine the prevalence of concordant diabetic comorbidities and to identify the associated factors among adult diabetic patients who have been on the follow-up at a diabetic clinic at Hiwot Fana Specialized University Hospital (HFSUH) which is located in Harari region, Eastern Ethiopia.

\section{Methods \\ Study Setting and Period}

The study was conducted from October 01 to 30, 2020 at HFSUH, which is situated in Harari regional state and 526 kilometers away from Addis Ababa, the capital of Ethiopia. The population of Harari region is estimated to be 183,344 people with 1:1 male to female ratio. ${ }^{24}$ These people are currently served by two public, two private, one police, and one non-government (Fistula) hospital in the region. In addition to those hospitals, there are eight health centers, 29 private clinics, 26 health posts, and one regional laboratory to serve the community of the region.

Of those, HFSUH is one of the two public hospitals found in the region and serves as the referral hospital for the 5.2 million catchment population of the Harari regional state and the East Hararghe zone of Oromia regional state. According to the data taken from the hospital, the diabetic clinic of HFSUH is open for service five days per week and provides services for more than 400 patients per year.

\section{Study Design and Populations}

Institutionalbased cross-sectional study design was used. All medical record charts of adult diabetic patients attending out-patient DM follow up clinic at HFSUH were taken as the source population. The study population was randomly selected medical record charts of adult DM patients 
who has been on follow up at diabetic clinic from September 30, 2019 to September 30, 2020. Of these, incomplete medical record charts were excluded.

\section{Sample Size Determination and Sampling Technique}

The sample size of the study was calculated with Epi Info version 7.1 using a single population proportion formula with the assumptions of $68.2 \%$ proportion of concordant diabetic comorbidity $^{25}$ at $95 \%$ confidence level, and $5 \%$ margin of error. Thus, a minimum of 333 participants were used to conduct the study. Similarly, the sample size for factors associated with concordant diabetic comorbidity among adult diabetic patient was computed with an assumptions; $Z \alpha / 2$, is the critical value of the normal distribution at $\alpha / 2$ (eg for a confidence level of $95 \%, \alpha$ is 0.05 and the critical value is 1.96), $Z \beta$ is the critical value of the Normal distribution at $\beta$ (eg for a power of $80 \%, \beta$ is 0.2 and the critical value is 0.84 ) and $\mathrm{p} 1$ and $\mathrm{p} 2$ are the expected sample proportions of the two groups. From these, $\mathrm{P} 1$ is the proportion of hypertension among male which is equal to $57.7 \%$ and $\mathrm{P} 2$ is the proportion of hypertension among female represented by $45.2 \%{ }^{25}$ Accordingly, the calculated sample size for the second objective of the study was 247 and 129 respectively. Finally the two results were compared and the largest sample size (333) participants were used for the study. To choose this number for the study, all lists of medical record numbers of diabetic patients on follow up at adult outpatient diabetic clinic of HFSUH from September, 30, 2019 to September, 30, 2020, were taken. To do so, first the list was wade from the log book and enumerated as the sample frame and then the study unit had been selected by using systematic random sampling method from them.

\section{Data Collection Tools and Procedure}

To collect pertinent data for the study, structured checklist was prepared by reviewing relevant literatures and patient's card. In doing so, information related to their socio-demographic characteristics (age, sex, residence, and educational level), type of diabetes, payment modality, duration of diabetes, treatment regimen, glycemic control and types of concordant comorbidities (hypertension, dyslipidemia, obesity, CKD and CVD were obtained. This data was collected based on the patient's medical record chart, and then the team participated to the collection of these relevant data incorporates ten medical internists supervised by investigators.

\section{Operational Definitions Concordant Comorbidity}

Is the presence or absence of at least one or more chronic conditions among diabetic patients. These are hypertension, obesity, dyslipidemia, cardiovascular disease, and/or CKD, among diabetic patients. ${ }^{8}$

\section{Hypertension}

Is documented systolic blood pressure (SBP) $\geq 140 \mathrm{mmHg}$ or diastolic blood pressure $\geq 90 \mathrm{mmHg}$ (at least two records in different days or four hours apart in a single day) or being on treatment for a physician diagnosed hypertension. $^{26}$

\section{Dyslipidemia}

Is the presence of at least one of the following: high plasma total cholesterol $>200 \mathrm{mg} / \mathrm{dl}$ (milligram per deciliter), high Low Density Lipoprotein -Cholesterol (LDL-C) $(>130 \mathrm{mg} / \mathrm{dl})$, low High Density Lipoprotein-Cholesterol (HDL-C) $(<40 \mathrm{mg} / \mathrm{dl}$ in men or $<50 \mathrm{mg} / \mathrm{dl}$ in women), and high triglyceride level $(>150 \mathrm{mg} / \mathrm{dl})$ or being on treatment for a physician's diagnosed dyslipidemia. ${ }^{27}$

\section{Chronic Kidney Disease}

Is defined as patients being on treatment and diagnosed by a physician, or urine dipstick protein $\geq+1$ at least two times in the last three months or serum creatinine level $\geq 1.2 \mathrm{miligram} /$ deciliter $(\mathrm{mg} / \mathrm{dl})$ in males and $\geq 1.0 \mathrm{mg} / \mathrm{dl}$ in females at least two times in the last three months. ${ }^{28}$

\section{Chronic Vascular Disease}

Is the presence of at least one of the following in diabetic patient: patients being on treatment after being diagnosed by a physician with stroke or ischemic heart disease, Electro cardio graph (ECG) finding of ischemic heart disease (ST elevation or pathological Q waves) or echocardiography finding of ischemic heart disease (wall motion abnormality or akinesia or hypokinesia or dyskinesia). ${ }^{27}$

\section{Good Glycemic Control}

Glycemic control is the recent (determined in less than three months) $\mathrm{HgA} 1 \mathrm{C}$ less than $7 \%$, or the last Fasting Blood Sugar (FBS $\leq 130 \mathrm{mg} / \mathrm{dl}$ ) in the absence of document $\mathrm{HgA} 1 \mathrm{C}$. $\mathrm{HgA} 1 \mathrm{C}>7 \%$ and/or FBS $>130 \mathrm{mg} / \mathrm{dl}$ is bad glycemic control. $^{8}$ 


\section{Data Quality Control}

Two days training was given for data collectors on components of the tool, data collection methods, and procedures before the actual data collection was conducted. To check the actual implementation of the procedures and the overall data collection process, the situation was closely followed by investigators. Finally, the completeness, the accuracy and the consistency of the collected data was checked on each day of the data collection period critically.

\section{Data Processing and Analysis}

After the data collection process was completed, it was transferred in to Epi data version 3.1., and then exported in to STATA version 16.0 for cleaning and analysis. Finally, descriptive analysis like frequency, percentage, and mean were used to describe the data. Binary logistic regression model was also applied to identify factors associated with DM comorbidities. Accordingly, those variables with the result of P-value $<0.05$ at bi-variable logistic regression analysis were considered for multivariable logistic regression analysis. Adjusted Odds Ratio (AOR) with 95\% Confidence Interval (CI) was used to measure strength of association and a variable with $p$-value $\leq 0.05$ was taken as statistically significant at multivariable logistic regression analysis.

\section{Results}

\section{Socio-Demographic Characteristics}

A total of 319 adult diabetic patents' medical charts were reviewed with the response rate of $95.7 \%$. Majority 170 (53.29\%) of the respondents were male, 149 (46.8\%) of them were female, and 173 (58.4\%) were urban residents. The mean age of the respondents was 44.94 years, but around one-third were within the age group of 35-54 years. Regarding the schemes of payments for treatments, more than half of the adult diabetic out-patients (53.29\%) were paying out-of-pocket (Table 1).

\section{Clinical Characteristics}

The mean duration of DM was $7.76(6.42 \pm \mathrm{SD} /$ Standard Deviation) years. The majority, $232(72.73 \%)$ of the DM patients were diagnosed for Type-II DM and 129 (40.44\%) were currently using oral hypoglycemic agents for the treatment of DM. Based on the clinical record review the mean FBS of the respondents was $156.20 \mathrm{mg} / \mathrm{dl}$. Glycemic control was calculated for the average of the last three records of FBS values. Accordingly the majority 183
Table I Socio-Demographic Characteristics of Adult Diabetic Out-Patients at Hiwot Fana Specialized University Hospital

\begin{tabular}{|l|l|l|l|}
\hline \multicolumn{2}{|l|}{ Variables } & Frequency & Percent \\
\hline Age in years & $18-24$ & 49 & 15.3 \\
& $25-34$ & 41 & 12.9 \\
& $35-54$ & 126 & 39.5 \\
& $\geq 55$ & 103 & 32.2 \\
\hline Sex & Male & 170 & 53.2 \\
& Female & 149 & 46.8 \\
\hline \multirow{2}{*}{ Residence } & Urban & 173 & 54.2 \\
& Rural & 146 & 45.8 \\
\hline \multirow{2}{*}{ Types of payment } & Fee waivers & 149 & 46.7 \\
& Out of pocket & 170 & 53.3 \\
\hline
\end{tabular}

(57.37\%) of the patients showed poor glycemic control (Table 2).

\section{Prevalence of Concordant Comorbidity}

The result of the study showed that the overall prevalence of concordant comorbidity among adult diabetic outpatients was 178, 55.8\% (95\% CI: 50.3-61.3). From this the study revealed that, hypertension $75(42.32 \%)$, obesity 39 (21.63\%), CVD 15 (8.15\%), dyslipidemia 7 (4.08\%), and CKD 19 (10.66\%) were reported comorbidities and 23 (13\%) patients have more than one comorbidities (Figure 1).

\section{Factors Associated with Concordant Comorbidities}

Binary logistic regression was applied to identify factors associated with the outcome variable. Accordingly, age, residence, types of DM, duration of treatment of DM, and glycemic control were factors significantly associated with DM comorbidity under bivariable logistic regression analysis at $\mathrm{P}$-value $<0.05$. However, under multivariate logistic regression analysis, age greater than 55 years, T2DM, and poor glycemic control was significantly associated with the outcome variable.

The odds of having concordant comorbidity among adult diabetic out-patients who were 55 or more years old was 7.52 times (AOR: 7.52, 95\% CI: 1.24, 45.75) more likely than those in the age group between 18 and 24 years old. Moreover, being T2DM patient resulted in increased odds of having concordant comorbidity. Adult diabetic out-patients with T2DM were 9.01 times (AOR: 
Table 2 Clinical Characteristics of Adult Diabetic Out-Patients at Hiwot Fana Specialized University Hospital

\begin{tabular}{|c|c|c|c|}
\hline \multicolumn{2}{|l|}{ Variables } & \multirow{3}{*}{$\begin{array}{l}\text { Frequency } \\
69 \\
250\end{array}$} & \multirow{3}{*}{$\begin{array}{l}\text { Percent } \\
21.63 \\
78.37\end{array}$} \\
\hline Body mass index & Overweight/obese & & \\
\hline & Normal/underweight & & \\
\hline \multirow[t]{2}{*}{ Glycemic control } & Controlled & 136 & 42.63 \\
\hline & Uncontrolled & 183 & 57.37 \\
\hline \multirow[t]{2}{*}{ Types of DM } & Type I DM ${ }^{\mathrm{a}}$ & 87 & 27.27 \\
\hline & Type II DM ${ }^{b}$ & 232 & 72.73 \\
\hline \multirow[t]{4}{*}{ Duration of treatment in years } & $\leq 1$ & 33 & 10.34 \\
\hline & $2-5$ & 109 & 34.17 \\
\hline & $6-10$ & 108 & 33.86 \\
\hline & $>10$ & 69 & 21.63 \\
\hline \multirow[t]{3}{*}{ Treatment for DM } & Insulin & 120 & 37.62 \\
\hline & Oral hypoglycemic agents & 129 & 40.44 \\
\hline & Both & 70 & 21.94 \\
\hline \multirow[t]{3}{*}{ Oral hypoglycemic agents } & Metformin & 103 & 51.76 \\
\hline & Glibenclimide & 6 & 3.02 \\
\hline & Both & 90 & 45.23 \\
\hline \multirow[t]{2}{*}{ Treatment of hypertension } & Yes & 112 & 35.11 \\
\hline & No & 308 & 96.55 \\
\hline \multirow[t]{6}{*}{ Anti-hypertensive drugs } & $\mathrm{ACEl}^{\mathrm{c}}$ & 44 & 39.29 \\
\hline & Angiotensin receptor blocker & 2 & 1.79 \\
\hline & Beta blockers & 1 & 0.89 \\
\hline & Diuretics & 12 & 10.71 \\
\hline & Calcium channel blockers & 10 & 8.93 \\
\hline & More than one medication & 43 & 38.39 \\
\hline \multirow[t]{2}{*}{ Primary prophylaxis for CVD } & Yes & 81 & 25.39 \\
\hline & No & 238 & 74.61 \\
\hline \multirow[t]{4}{*}{ Urine dipstick protein } & Negative & 264 & 82.76 \\
\hline & +1 & 35 & 10.97 \\
\hline & +2 & 15 & 4.70 \\
\hline & +3 & 5 & 1.57 \\
\hline \multirow[t]{2}{*}{ Treatment of ischemic heart disease } & Yes & 22 & 6.90 \\
\hline & No & 297 & 93.10 \\
\hline \multirow[t]{2}{*}{ Treatment of Stroke } & Yes & 11 & 3.45 \\
\hline & No & 172 & 80.4 \\
\hline \multirow[t]{2}{*}{ Echocardiography feature of ischemia } & Yes & 19 & 5.96 \\
\hline & No & 300 & 4.04 \\
\hline
\end{tabular}

Notes: ${ }^{a}$ Type I diabetes mellitus, btype 2 diabetes mellitus, 'angiotensin converting enzyme inhibitors.

9.01, 95\% CI: $1.50,54.04)$ more likely develop concordant comorbidity when compared to those patients with T1DM.

Also the study depicted that duration of diabetes of more than 10 years was significantly risk for having concordant comorbidity. Moreover, respondents who had 2 to 5 years duration of DM treatments were 77\% less (AOR: $0.23,95 \%$
CI: $0.08,0.69)$ likely develop concordant comorbidities when compared with those who were more than 10 years on treatment. Likewise, the odds of having concordant comorbidity among adult diabetic out-patients of poor glycemic control was 4.41 times (AOR: 4.4 1, 95\% CI: 2.34, 8.32) greater than those of good glycemic control (Table 3 ). 


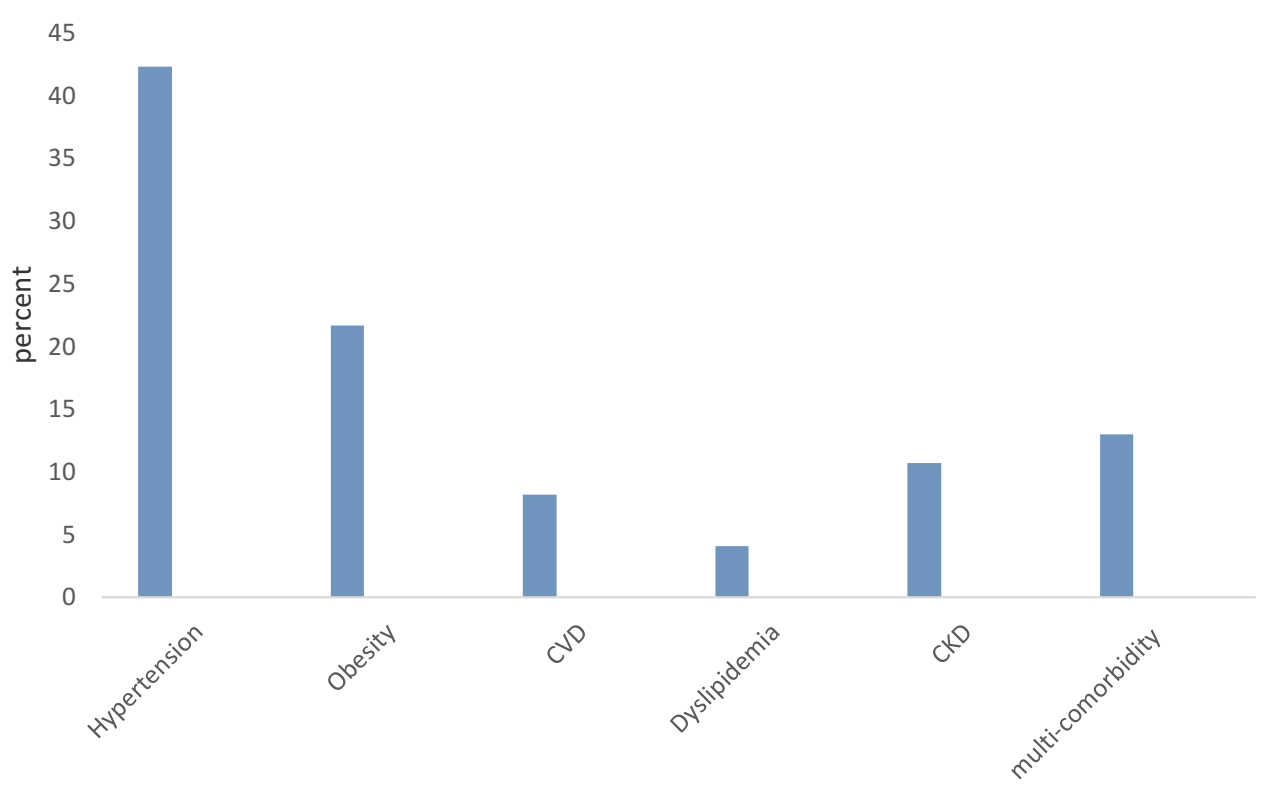

Figure I Distribution of comorbid diseases among adult diabetic out-patients at Hiwot Fana Specialized University Hospital.

\section{Discussion}

In the present study, a high prevalence of concordant comorbidities among adult diabetic out-patients, 55.8\% (95\% CI: 50.3-61.3) was observed. This is lower than the findings of studies conducted in different parts of the world. For instance, in Switzerland, 91\%, ${ }^{29}$ in Spain, $82 \%,{ }^{30}$ in India, $84 \%,{ }^{31}$ in Netherland, $84.6 \%,{ }^{32}$ and in Unites States of America (USA), 88.5\%. ${ }^{16}$ In contrast to those findings, the result of this study is slightly higher as compared to the previous cross-sectional study done in Scotland $(42.2 \%) .{ }^{33}$ The variation across studies might be observed due to the difference in the target population. That is most of the previous studies used only patients with T2DM; however this study considered both types of DM. Furthermore, the context of socio-demographic variations and methodologies used might be the cause for the differences. $^{19}$

The current study signifies age as one of the identified factors associated with developing comorbidities among DM patients. Accordingly, the odds of having concordant comorbidity among adult diabetic out-patients who were 55 and more years old were higher as compared to those in age group of 18-24 years. However, consistent results were reported by Tinetti et al(2012), who found that the existence of comorbidity increased substantially with age and was observed in most people aged 65 years and more $^{33}$ Another evidence generated by Barnett et al (2012), concluded that more than $75 \%$ of individuals at the age of 65 years and above have multiple chronic conditions, but it is less frequently observed on young age groups. ${ }^{34}$ Moreover, the retrospective study carried out in Saudi Arabia had shown that most of the comorbidities were found at the age of 45 years and above. ${ }^{35}$ Also the same study result was reported from Germany. ${ }^{36}$ This might be due to as age increase blood vessels become hard, losing their elasticity and more stiffened and leads to cardiovascular complications. Moreover, the glomerular filtration rate is also decreases with age and leads renal complications. $^{37,38}$

The current study revealed that the types of DM is linked with the existence of concordant comorbidity among diabetic patient. Those patients with T2 DM are more likely develop concordant comorbidity as compared to those with T1DM. The current result is consistent with studies done in North Eastern Italy $^{39}$ and the Spain. ${ }^{30}$ Their study reported that having T2DM was a risk factor for the occurrence of comorbidity. This might be due to high atherogenesis, dyslipidemia, and insulin resistance in T2DM. ${ }^{13,40-42}$

The finding of the current study documented that the longer duration of diabetes treatment is a associated with DM comorbidity. This result is in agreement with a study done in Malaysia ${ }^{43}$ and Debre Tabor General Hospital of Ethiopia $^{40}$ which noted and stressed that a longer duration of DM treatment contributes to increased risk for diabetes complications. In consonance to this finding by Jelinek et al(2017) reported that the longer duration of diabetics increase in the risk of complications. ${ }^{11}$ This might be 
Table 3 Multivariable Logistic Regression Analysis for Factors Associated with Concordant Comorbidities Among Adult Diabetic Out-Patients at Hiwot Fana Specialized University Hospital

\begin{tabular}{|c|c|c|c|c|c|}
\hline \multicolumn{2}{|l|}{ Variables } & \multicolumn{2}{|c|}{ DM $^{\mathrm{a}}$ Concordant Comorbidity } & \multirow{3}{*}{$\begin{array}{l}\operatorname{COR}^{b}\left(95 \% \mathrm{CI}^{\mathrm{c}}\right) \\
\mathrm{I} \\
3.16(0.89,11.18) \\
17.1(5.78,50.5 \mathrm{I}) \\
7.5 \mathrm{I}(20.25,40.88)\end{array}$} & \multirow{3}{*}{$\begin{array}{l}\operatorname{AOR}^{d}(95 \% \mathrm{CI}) \\
I \\
1.63(0.39,6.77) \\
3.40(0.67,17.37) \\
7.52(1.24,45.75)\end{array}$} \\
\hline & & No & Yes & & \\
\hline Age in years & $\begin{array}{l}18-24 \\
25-34 \text { years } \\
35-54 \text { years } \\
\geq 55 \text { years }\end{array}$ & $\begin{array}{l}45(31.91) \\
32(22.70) \\
50(35.46) \\
14(9.93)\end{array}$ & $\begin{array}{l}4(2.25) \\
9(5.06) \\
76(42.70) \\
89(50.00)\end{array}$ & & \\
\hline Residence & $\begin{array}{l}\text { Urban } \\
\text { Rural }\end{array}$ & $\begin{array}{l}68(48.23) \\
73(51.77)\end{array}$ & $\begin{array}{l}105(58.99) \\
73(41.01)\end{array}$ & $1.54(0.1 .14,2.10)$ & $\begin{array}{l}\text { I } \\
0.79(0.43,1.46)\end{array}$ \\
\hline Types of DM & $\begin{array}{l}\text { TIDM } \\
\text { T2DM }\end{array}$ & $\begin{array}{l}74(52.48) \\
67(47.52)\end{array}$ & $\begin{array}{l}13(7.30) \\
165(92.70)\end{array}$ & $\begin{array}{l}\text { I } \\
\text { II } 4.0 \mid(0.7 .29,26.97)\end{array}$ & $\begin{array}{l}\text { I } \\
9.01(1.50,54.04)\end{array}$ \\
\hline Duration of treatment in a year & $\begin{array}{l}\leq 1 \\
2-5 \\
6-10 \\
\geq 10\end{array}$ & $\begin{array}{l}18(12.77) \\
75(53.19) \\
39(27.66) \\
9(6.38)\end{array}$ & $\begin{array}{l}15(8.43) \\
34(19.10) \\
69(38.76) \\
60(33.71)\end{array}$ & $\begin{array}{l}0.125(0.05,0.33) \\
0.068(0.03,0.15) \\
0.26(0.1121 .0 .59) \\
1\end{array}$ & $\begin{array}{l}0.28(0.075,1.08) \\
0.23(0.08,0.69) \\
0.61(0.22,1.70) \\
1\end{array}$ \\
\hline Treatment for DM & $\begin{array}{l}\text { Insulin } \\
\text { Oral hypoglycemic agents } \\
\text { Both }\end{array}$ & $\begin{array}{l}77(54.61) \\
47(33.33) \\
17(12.06)\end{array}$ & $\begin{array}{l}43(24.16) \\
82(46.07) \\
53(29.78)\end{array}$ & $\begin{array}{l}\text { I } \\
3.12(1.86,5.24) \\
5.58(2.88,10.82)\end{array}$ & $\begin{array}{l}\text { I } \\
0.63(0.14,2.77) \\
0.36(0.08,1.62)\end{array}$ \\
\hline Glycemic control & $\begin{array}{l}\text { Controlled } \\
\text { Uncontrolled }\end{array}$ & $\begin{array}{l}94(66.67) \\
47(33.33)\end{array}$ & $\begin{array}{l}42(23.60) \\
136(76.40)\end{array}$ & $\begin{array}{l}\text { I } \\
6.48(3.96, \mid 0.59) \mid\end{array}$ & $\begin{array}{l}\text { I } \\
4.4 \text { I }(2.34,8.32)\end{array}$ \\
\hline
\end{tabular}

Notes: a Diabetes mellitus, ${ }^{b}$ crude odd ratio, ${ }^{c}$ confidence interval, ${ }^{d}$ adjusted odd ratio.

linked with changes caused by DM such as micro-vascular damage, sympathetic damage, an enhanced Renin Angiotesin and Aldosterone system(RAAS), and decreased insulin sensitivity which will get worse with longer duration of $\mathrm{DM}^{31}$

The current study identified that glycemic control is another determinant factor for the experience of comorbidities among DM patients. For instance an odd of having concordant comorbidity among adult diabetic out-patients of poor glycemic control was four times greater than those of good glycemic control. In line of this finding a consistent result was reported by a cross-sectional study conducted in Jimma University Specialized University Hospital. The result has shown that poor glycemic control was significantly associated with risk of comorbidity among adult diabetic patients. $^{44}$ This finding is also in agreement with the study that was conducted in Debre Tabor General Hospital, Ethiopia. ${ }^{40}$ This might be due to excess glucose chemically attaches to free amino groups of proteins collagen and other long lived proteins in blood vessel walls which trap circulating low density lipoprotein that promotes the deposition of cholesterol in the intima thus accelerates atherogenesis. Hyperglycemia also increases the osmolality of the extracellular fluid which trigger water to shifts from the intracellular to extracellular space and cause volume expansion and high blood pressure. $^{45}$

A better understanding of diabetic-related comorbidities and their associated factors can enhance the type and capacity of medical health care utilization.

However, the limitation of this work is that a crosssectional nature of the study makes some variables less explanatory and its cause-effect relationships cannot be measured. Also the study included only certain comorbidities due to the lack of data from patient's medical record chart on other diabetic related complications. For instance, retinopathy.

\section{Conclusion and Recommendations}

Consistent with previous studies, the current findings showed that patients with diabetes have a high prevalence of concordant comorbidity. Moreover, age, types of DM, duration of treatment, and glycemic control were identified as independent predictors of concordant comorbidity. Therefore, health care providers caring for DM patients should take comorbid conditions into account since it is the rule rather than the exception. They have to give due attention for diabetic patients with comorbidity or at risk to develop comorbidities like patients with older in age, T2DM, and 
being on follow up for long period of time. Also, prevention of comorbidities among diabetic patients needs screening, early identification, and managements as components of comprehensive diabetes care and life style modification is the other strategy to prevent comorbidities among diabetic patients. Finally, we recommend researchers to conduct study with advanced designs on the issue for further investigation and extra suggestion.

\section{Data Sharing Statement}

The data set used for the analysis could be accessible from the corresponding author on reasonable request.

\section{Ethical Approval}

This study was conducted in accordance with the Declaration of Helsinki-Ethical principle for medical research involving the human subjects. Accordingly, the ethical clearance was obtained from the Haramaya University, College of Health nd Medical Sciences, Institutional Health Research Ethics Review Committee (IHRERC) with a reference number of (IHRERC/232/ 2020). An official letter was sent to HFSUH and informed voluntary consent was received from the head of the HFSUH and medical record office. The personal identifiers were excluded, information gained was kept confidential and used for the proposed study only.

\section{Acknowledgment}

We would like to thank Haramaya University College of Health and Medical science, for giving us an opportunity to conduct this study. Also, we extend our gratitude to the data collectors for their kind, loyal and honest contribution.

\section{Author Contributions}

All the authors made a significant contribution to the work reported equally: conception, study design, execution, and acquisition of data, analysis and interpretation. Also they equally took part in drafting, revising or critically reviewing the work. Moreover, they have made a mutual agreement on the journal to which the article has been submitted for publication. Finally, they agreed to share equal responsibility to be accountable for all aspects of the work and send the final approved version for the publication.

\section{Funding}

The study was funded by Haramaya University. But, the funding institution has no role in the publication consent or approval.

\section{Disclosure}

The authors report no conflicts of interest in this work.

\section{References}

1. World Health Organization. Definition and diagnosis of diabetes mellitus and intermediate hyperglycaemia: report of a WHO/IDF consultation. 2006.

2. American Diabetes Association. Standards of medical care in diabetes. J Clin Appl Res Educ. 2018;41:150.

3. Tandon N, Anjana RM, Mohan V, et al. The increasing burden of diabetes and variations among the states of India: the Global Burden of Disease Study 1990-2016. Lancet Glob Health. 2018;6(12): e1352-e1362. doi:10.1016/S2214-109X(18)30387-5

4. World Health Organisation. Global report on diabetes. Glob Rep Diabetes. 2020.

5. Lin X, Xu Y, Pan X, et al. Global, regional, and national burden and trend of diabetes in 195 countries and territories: an analysis from 1990 to 2025. Sci Rep. 2020;10(1):1-11. doi:10.1038/s41598-019$56847-4$

6. International Diabetes Federation. IDF Diabetes Atlas. 8th edition. International Diabetes Federation; 2017: 1-150.

7. Bishu KG, Jenkins C, Yebyo HG, Atsbha M, Wubayehu T, Gebregziabher M. Diabetes in Ethiopia: a systematic review of prevalence, risk factors, complications, and cost. Obes Med. 2019;15:100132. doi:10.1016/j.obmed.2019.100132

8. American Diabetes Association. Standards of medical care in diabetes. J Clin Appl Res Educ. 2019;42(Supplement 1):S1-S193.

9. Du Y, Heidemann C, Gößwald A, Schmich P, Scheidt-Nave C. Prevalence and comorbidity of diabetes mellitus among non-institutionalized older adults in Germany - results of the national telephone health interview survey'German Health Update (GEDA)' 2009. BMC Public Health. 2013;166:1-13.

10. Aga F, Dunbar SB, Tedla Kebede RAG, Gary R. The role of concordant and discordant comorbidities on performance of self-care behaviors in adults with type 2 diabetes: a systematic review. Diabetes Metabol Syndr Obes. 2019;12:333. doi:10.2147/DMSO.S186758

11. Jelinek HF, Osman WM, Khandoker AH, et al. Clinical profiles, comorbidities and complications of type 2 diabetes mellitus in patients from United Arab Emirates. BMJ Open Diabetes Res Care. 2017;5(1):e000427. doi:10.1136/bmjdrc-2017-000427

12. Kerr EA, Heisler M, Krein SL, et al. Beyond comorbidity counts: how do comorbidity type and severity influence diabetes patients' treatment priorities and self-management? J Gen Intern Med. 2007;22(12):1635-1640. doi:10.1007/s11606-007-0313-2

13. Khan A, Uddin S, Srinivasan U. Comorbidity network for chronic disease: a novel approach to understand type 2 diabetes progression. Int J Med Inform. 2018;115:1-9. doi:10.1016/j.ijmedinf.2018.04.001

14. Simpson SH, Corabian P, Jacobs P, Johnson JA. The cost of major comorbidity in people with diabetes mellitus. Cmaj. 2003;168 (13): 1661-1667.

15. Kong AP, Xu G, Brown N, So W-Y, Ma RC, Chan JC. Diabetes and its comorbidities-where East meets West. Nat Rev Endocrinol. 2013;9(9):537. doi:10.1038/nrendo.2013.102

16. Iglay K, Hannachi H, Joseph Howie P, et al. Prevalence and co-prevalence of comorbidities among patients with type 2 diabetes mellitus. Curr Med Res Opin. 2016;32(7):1243-1252. doi:10.1185/ 03007995.2016.1168291

17. Ekoru K, Doumatey A, Bentley AR, Chen G, Zhou J, Shriner D. Type 2 diabetes complications and comorbidity in Sub-saharan Africans. EClinicalMedicine. 2019;16:30-41.

18. Kengne AP, Echouffo-Tcheugui J-B, Sobngwi E, Mbanya J-C. New insights on diabetes mellitus and obesity in Africa-Part 1: prevalence, pathogenesis and comorbidities. Heart. 2013;99(14):979-983. doi:10.1136/heartjnl-2012-303316 
19. Papanas N, Ziegler D. Risk factors and comorbidities in diabetic neuropathy: an update 2015. Rev Diabetic Stud. 2015;12(1-2):48. doi:10.1900/RDS.2015.12.48

20. Tripathy JP, Thakur J, Jeet G, Jain S. Prevalence and determinants of comorbid diabetes and hypertension: evidence from non communicable disease risk factor STEPS survey, India. Diabetes Metabol Syndr. 2017;11:S459-S465. doi:10.1016/j.dsx.2017.03.036

21. Piette JD, Kerr EA. The impact of comorbid chronic conditions on diabetes care. Diabetes Care. 2006;29(3):725-731.

22. Huang ES. Management of diabetes mellitus in older people with comorbidities. BMJ. 2016;353. doi:10.1136/bmj.i2200

23. Ekoru K, Doumatey A, Bentley AR, et al. Type 2 diabetes complications and comorbidity in Sub-Saharan Africans. EClinicalMedicine. 2019;16:30-41. doi:10.1016/j.eclinm.2019.09.001

24. Central Statistical Agency. Central statistical agency ethiopia census. 2007.

25. Belay E, Abera A, Mehari A, Gebremeskel G, Endrias A, Endris K. Achievements of diabetes goals and their determinants in type 2 diabetic patients attending outpatient diabetic clinic in northern Ethiopia. Int J Chronic Dis. 2017;2017:1-8. doi:10.1155/2017/5713187

26. European Society of Hypertension E. Guidelines for the management of arterial hypertension. Eur Heart J. 2018;1-98.

27. American College of Cardiology. A Guideline on the Management of Blood Cholesterol. 2018.

28. American Family Physician. A chronic kidney disease: detection and evaluation. AFP J. 2017;12:776-783.

29. Huber CA, Diem P, Schwenkglenks M, Rapold R, Reich O. Estimating the prevalence of comorbid conditions and their effect on health care costs in patients with diabetes mellitus in Switzerland Diabetes Metabol Syndr Obes. 2014;7:455. doi:10.2147/DMSO. S69520

30. Mata-Cases M, Franch-Nadal J, Real J, Cedenilla M, Mauricio D. Prevalence and coprevalence of chronic comorbid conditions in patients with type 2 diabetes in Catalonia: a population-based cross-sectional study. BMJ Open. 2019;9(10):e031281. doi:10.1136/ bmjopen-2019-031281

31. Pati S, Schellevis F, Marengoni A. Prevalence and pattern of co morbidity among type 2 diabetics attending urban primary healthcare centers at Bhubaneswar (India). PLoS One. 2017;12(8):e0181661. doi:10.1371/journal.pone.0181661

32. Luijks H, Schermer T, Bor H, et al. Prevalence and incidence density rates of chronic comorbidity in type 2 diabetes patients: an exploratory cohort study. BMC Med. 2012;10(1):1-10. doi:10.1186/17417015-10-128

33. Tinetti ME, Fried TR, Boyd CM. Designing health care for the most common chronic condition-multimorbidity. JAMA. 2012;307 (23):2493-2494. doi:10.1001/jama.2012.5265

34. Barnett K, Mercer SW, Norbury M, Watt G, Wyke S, Guthrie B. Epidemiology of multimorbidity and implications for health care, research, and medical education: a cross-sectional study. Lancet. 2012;380:37-43. doi:10.1016/S0140-6736(12)60240-2
35. Alshaya AK, Alsayegh AK, Alshaya HK, et al. The common complications and comorbidities among Saudi diabetic patients in Northern Saudi Arabia. Open $J$ Endocr Metabol Dis. 2017;7:151-161. doi:10.4236/ojemd.2017.77014

36. Du Y, Heidemann C, Gößwald A, Schmich P, Scheidt-Nave C. Prevalence and comorbidity of diabetes mellitus among non-institutionalized older adults in Germany-results of the national telephone health interview survey 'German Health Update (GEDA)'2009. BMC Public Health. 2013;13(1):1-13. doi:10.1186/1471-2458-13-166

37. Caughey GE, Roughead EE, Vitry AI, McDermott RA, Shakib S, Gilbert AL. Comorbidity in the elderly with diabetes: identification of areas of potential treatment conflicts. Diabetes Res Clin Pract. 2010;87(3):385-393. doi:10.1016/j.diabres.2009.10.019

38. Piccirillo JF, Vlahiotis A, Barrett LB, Flood KL, Spitznagel EL, Steyerberg EW. The changing prevalence of comorbidity across the age spectrum. Crit Rev Oncol Hematol. 2008;67(2):124-132. doi:10.1016/j.critrevonc.2008.01.013

39. Valent F, Tillati S, Zanier L. Prevalence and comorbidities of known diabetes in northeastern I taly. $J$ Diabetes Investig. 2013;4 (4):355-360. doi:10.1111/jdi.12043

40. Belsti Y, Akalu Y, Fekadu H, Animut Y. Awareness of complications of diabetes mellitus and its associated factors among type 2 diabetic patients at Addis Zemen District Hospital, Northwest Ethiopia. BMC Res Notes. 2019;12(1):1-7. doi:10.1186/s13104-019-4637-X

41. El-Kebbi IM, Ziemer DC, Cook CB, Miller CD, Gallina DL, Phillips LS. Comorbidity and glycemic control in patients with type 2 diabetes. Arch Intern Med. 2001;161(10):1295-1300. doi:10.1001/ archinte.161.10.1295

42. Gazzaz ZJ, Iftikhar R, Jameel T, Baig M, Murad MA. Association of dyslipidemia and comorbidities with risk factors among diabetic patients: a retrospective analysis. Diabetes Metabol Syndr Obes. 2020;13:935. doi:10.2147/DMSO.S235546

43. Muhamad NA, Mutalip MHA, Mustapha N, et al. Association between comorbidities and selected sociodemographic factors with complications of diabetes: results from the National Diabetic Registry Malaysia. J Diabetes Mellitus. 2018;8(3):84-97. doi:10.4236/ jdm.2018.83009

44. Tamiru S, Alemseged F. Risk factors for cardiovascular diseases among diabetic patients in southwest Ethiopia. Ethiop J Health Sci. 2010;20(2):121-128. doi:10.4314/ejhs.v20i2.69438

45. Wolfsdorf JI, Glaser N, Agus M, et al. ISPAD clinical practice consensus guidelines 2018: diabetic ketoacidosis and the hyperglycemic hyperosmolar state. Pediatr Diabetes. 2018;19:155-177.

Diabetes, Metabolic Syndrome and Obesity: Targets and Therapy

Dovepress

\section{Publish your work in this journal}

Diabetes, Metabolic Syndrome and Obesity: Targets and Therapy is an international, peer-reviewed open-access journal committed to the rapid publication of the latest laboratory and clinical findings in the fields of diabetes, metabolic syndrome and obesity research. Original research, review, case reports, hypothesis formation, expert opinion and commentaries are all considered for publication. The manuscript management system is completely online and includes a very quick and fair peer-review system, which is all easy to use. Visit http://www.dovepress.com/testimonials.php to read real quotes from published authors. 